Nudged by a Robot:

Responses to Agency and Feedback

\author{
Iis Tussyadiah \\ Reader in Hospitality and Digital Experience \\ School of Hospitality and Tourism Management \\ University of Surrey \\ Stag Hill Campus \\ Guildford, GU2 7XH, United Kingdom \\ Email: i.tussyadiah@surrey.ac.uk
}

\author{
And \\ Graham Miller \\ Professor of Sustainability in Business \\ School of Hospitality and Tourism Management \\ University of Surrey \\ Stag Hill Campus \\ Guildford, GU2 7XH, United Kingdom \\ Email: g.miller@surrey.ac.uk
}

Accepted for publication in

Annals of Tourism Research

05 July 2019 


\section{Nudged by a Robot: \\ Responses to Agency and Feedback}

\section{Highlights}

- Intentional agents provide surveillance and agency cues to hotel guests

- Agents can be leveraged to provide intervention for sustainable behavior

- Virtual assistants and robots do not lead to different intervention outcomes

- Social feedback given by a virtual assistant was effective at inducing intention

- $\mathrm{AI}$ and robotic technologies can be used to foster sustainable tourist behavior 


\title{
Nudged by a Robot: \\ Responses to Agency and Feedback
}

\begin{abstract}
The availability of always-on digital agents in hotel rooms, providing agency and surveillance cues, presents opportunities for behavioral interventions. This study tested the effectiveness of agency and social feedback on pro-environmental behavior intention of hotel consumers. A survey with scenariobased experimental design was distributed to US and UK travelers ( $N=621)$. Results suggest that no one type of agent was more effective than the other in influencing pro-environmental behavior intention. Social feedback was found effective when given by a virtual assistant. Perception of another agent being 'present' in the room, even when invisible, is sufficient to induce normative behavior. This enriches literature on surveillance cues and behavior change and contributes to finding new ways of leveraging emerging technologies to foster sustainability.
\end{abstract}

Keywords: virtual assistant; robot; surveillance psychology; behavior change intervention; resource conservation; sustainable tourism

\section{Introduction}

With the growing force of travel and tourism worldwide comes significant challenges to reduce the environmental burdens of tourism activities and make tourism a catalyst for positive change toward sustainability (UNWTO, 2018). One of key priorities in tourism development is ensuring significant environmental benefits of the sector, focusing on ways to reduce water consumption, energy use, and carbon emission, as well as addressing the need to preserve biodiversity and heritage (UNWTO, 2011; 2012). To address these, a concerted effort from all stakeholders in the travel and tourism ecosystem, where each endeavors to take part through enactment of environmentally beneficial policy, investment, and other initiatives, is needed. In hotels, there have been tremendous efforts toward developing technological solutions for green infrastructure and innovative operations, as well as other green practices to improve resource efficiency (Kim, Hlee, \& Joun, 2016). One of these is promoting positive behavior change to hotel guests through interventions and nudges targeting such behaviors as energy conservation and towel reuse (e.g., Chang, Huh, \& Lee, 2015; Reese, Loew, \& Steffgen, 
2014). Previous studies have suggested that the accommodation sectors account for the most significant consumption of resources and, as such, generate a substantial share of the environmental impacts of tourism (Bohdanowicz \& Martinac, 2007; Gössling, 2002). As the main actors driving resource consumption in tourism destinations, tourists thus have a fundamental role in the effort to promote sustainability (Nisa, Varum, \& Botelho, 2017).

According to Schultz (2014), most environmental problems have their origins in human behavior. Behavior change is thus required for any solutions to these problems. With technological advances in ambient intelligence, sensors, and internet-of-things, an emerging approach is to use intelligent solutions for behavior change interventions (He, Greenberg, \& Huang, 2009). Furthermore, the integration of artificial intelligence (AI) and robotics into voice-activated virtual assistant or inroom companion robot is one of the latest developments in intelligent hotel rooms that presents a new opportunity for interventions. Not only that these agents can be programmed to provide feedback, which has been proven effective in influencing positive behavior change (Karlin, Zinger, \& Ford, 2015), but also that the presence of a social agent in the room, also known as automated social presence (van Doorn et al., 2017), can induce feeling of being watched (cues of surveillance), which could trigger more socially desirable behaviors (Bateson et al., 2013). Since this intervention approach has not been implemented to date, it is of theoretical and practical importance to assess its potential effectiveness.

Previous studies have identified intervention approaches that are consistently effective at inducing behavior change: social norms and nudges (Nisa, Varum, \& Botelho, 2017; Ölander \& Thøgersen, 2014), feedback (Karlin, Zinger, \& Ford, 2015), and cues of agency or surveillance from intentional agents (i.e., intelligent machines designed for social interactions) (Krátský et al., 2016). Taking these into consideration, this study aims to investigate the effect of interventions involving intentional agents in hotel rooms that provide feedback on pro-environmental behavior. Specifically, this study examines the effectiveness of using different intentional agents (virtual assistant vs. robot) and of providing social feedback (presence vs. absence of social feedback) at inducing proenvironmental behavioral intention in hotel guests. This research is designed to compare people's reaction to feedback from a robot (an embodied agent) and those from a virtual assistant (a 
disembodied/pervasive agent). This carries a theoretical significance in terms of how effective the two types of intentional agents are in influencing human behavior. The findings indicate no direct significant effects of types of intelligent agents and presence or absence of social feedback on guests' pro-environmental behavior intention. However, positive interaction effect between social feedback and virtual assistant was found. The results inform hotels how to design intelligent agents to influence guests' behavior.

\section{Pro-environmental Behavior Interventions}

The effectiveness of interventions in enticing intention and actual behavior associated with resource conservation among hotel guests has been evidenced in various studies (Nisa, Varum, \& Botelho, 2017; Scheibehenne, Jamil, \& Wagenmakers, 2016). Chang, Huh, and Lee (2015) found that behavioral intentions toward electricity conservation were more pronounced when a nudge was provided in hotel rooms. Baca-Motes et al. (2013) revealed that a small, carefully planned intervention, such as giving guests a lapel pin to symbolize commitment to environmentally friendly behavior, had a significant impact on towel reuse behavior. Reese, Loew, and Steffgen's (2014) study demonstrated that guests receiving messages augmented with statements reflecting provincial norms (i.e., focusing on the behavior of fellow guests) used less towel than those receiving standard environmental messages. More recently, from an experiment in self-contained bed-and-breakfast (B\&B) style accommodation, Warren et al. (2018) revealed that guests receiving sustainability advice and communication saved more electricity, gas, water, and firewood when compared to those who did not receive feedback. While outcomes and magnitudes of intervention effects in these individual studies vary, a consensus can be drawn that providing behavioral interventions is effective in bringing about responsible behavior in hotel guests, thus fostering environmental sustainability (Nisa, Varum, \& Botelho, 2017; Scheibehenne, Jamil, \& Wagenmakers, 2016).

Due to its strategic implications for the success of sustainability practices in hotels, an evaluation of relative effectiveness of various intervention strategies, including widely implemented approaches and emerging ones, is important. In a systematic review and meta-analysis with nine studies testing interventions targeting towel reuse, Nisa, Varum, and Botelho (2017) found 19 
interventions and categorized them into five strategies: social norms, commitment, donation, environmental appeal, and choice architecture. They further demonstrated consistent positive effects of interventions involving social norms and nudges, while those using commitment, environmental appeal, and donations were found ineffective. In a previous review utilizing Bayesian Evidence Synthesis (BES) on seven studies implementing social norms for towel reuse, Scheibehenne, Jamil, and Wagenmakers (2016) suggested that when analyzed together, the findings from these studies provide strong support that descriptive social norms can be effective in positive behavior change. This finding, however, was disputed by Carlsson et al. (2016), demonstrating that the method used in Scheibehenne, Jamil, and Wagenmakers's (2016) study resulted in overstatement of the pooled effects. Using Bayes Multilevel Meta-Analysis to re-analyze the studies, Carlsson et al. (2016) suggested that the evidence of small effect of social norms on towel reuse behavior is inconclusive. Nonetheless, most recent conclusion from Nisa, Varum and Botelho's (2017) study, which used random effects meta-analysis technique, stated that social norms are consistently effective in promoting towel reuse rate, albeit with modest effects. This is consistent with the results from Farrow, Grolleau, and Ibanez's (2017) study, which identified consistent effects of social norms at inducing significant changes in a broader scope of pro-environmental behaviors, including energy use, recycling, and other behaviors (green consumption, water conservation, towel reuse, etc.).

Today, innovation in sensors and smart metering systems provides opportunity for hotels to improve resource efficiency through automatic detection and reduction of excess consumption. For example, using microphone arrays and motion detectors to monitor the environment (e.g., temperature, luminance), lights and TV can switch off automatically when guests leave the room. Moreover, some of these technologies are designed to provide real time feedback to their users, often referred to as eco-feedback technologies (Froehlich, Findlater, \& Landay, 2010; He, Greenberg, \& Huang, 2009). Examples include sensors placed in showers and taps to inform guests of water intake (e.g., HydroSense; Hawrylak et al., 2015) and mobile apps with computational feedback system for more sustainable trip mode and route choice (e.g., Quantified Traveler; Jariyasunant et al., 2015). Indeed, the experiment by Warren et al. (2018) leveraged the feedback mechanism of high resolution smart meter monitoring system to provide sustainability advice in tourist accommodation. In a more 
general setting, Karlin, Zinger, and Ford's (2015) meta-analysis results demonstrated that feedback is consistently effective in promoting energy conservation.

The most recent technological advancement in AI and robotics has led hotels to adopt virtual assistants and service robots to provide assistance to their guests (Ivanov et al., 2019; Ivanov, Webster, \& Berezina, 2017; Tussyadiah \& Park, 2018). In 2016, Starwood Hotels \& Resorts introduced Project Jetson, equipping hotel rooms at Aloft Boston Seaport and Aloft Santa Clara in California with Apple Siri, allowing guests to give voice commands to control in-room amenities (Kim, 2016). The Wynn Las Vegas has placed thousands of Amazon Echo in its rooms (Gibson, 2017) and select rooms in Henn na Hotel properties in Japan have voice-activated in-room companion robot with similar functionalities. Research has demonstrated the significant roles of service robots in engaging consumers on a social level, further influencing their experiences (see van Doorn et al., 2017). More importantly, several studies have found that presenting cues of surveillance and agency, through the use of social agents, can be effective in influencing human behavior (Boyd, Richerson, \& Henrich, 2011; Ernest-Jones, Nettle, \& Bateson, 2011; Krátský et al., 2016). Identifying whether and how intelligent agents in hotel rooms could be utilized to influence guests' pro-environmental behavior is therefore crucial for both theory (a better understanding of how to influence human behavior) and practice (a better understanding of how to design effective interventions).

\section{The Watching-Eyes Effect}

The watching-eyes effect refers to the phenomenon that people tend to behave more pro-socially when artificial surveillance cues, such as an image of watching eyes, are present in their environment (Haley \& Fessler, 2005; Pfattheicher \& Keller, 2015). Theoretically speaking, the watching-eyes effect can be attributed to reputation-based partner choice models of the evolution in social cooperation (Roberts, 1998). These models suggest that people act pro-socially as an investment in their social reputation. A good reputation increases the likelihood of being favored by others for inclusion in future interactions. Therefore, pro-social behavior is fitness enhancing, allowing people to be more socially desirable (Boyd, Richerson, \& Henrich, 2011; Krátský et al., 2016). As being monitored by social others increases the reputational consequences of an action, people are sensitive 
to whether or not they are being monitored. Artificial watching eyes exploit this sensitivity and bring about the tendency that people will always increase the level of their pro-sociality when being watched (Ernest-Jones, Nettle, \& Bateson, 2011).

Another explanation comes from norm psychology (Chudek \& Henrich, 2011), the coupling of people's sensitivity to locally-specific behavioral norms and a tendency to sanction departures from these norms. The presence of an observer increases the probability of being punished by not adhering to local norms. Therefore, providing artificial watching eyes exploits the feeling of being watched, leading to people behaving more normatively (Bateson et al., 2013). Such cues affect behavioral responses in subtle, probably unconscious ways (Bargh, 2014). When consistent, both the prosociality and norm psychology hypotheses predict the same outcome: cues of intentional agents will increase pro-social behavior. However, in situations where local norm is not to be pro-social, the norm psychology hypothesis will predict that surveillance cues decrease pro-social behavior, while pro-sociality hypothesis will predict otherwise (Bateson et al., 2013).

Studies have provided evidence of watching-eyes effects in altruistic behavior, such as generosity (Haley \& Fessler, 2005; Keller \& Pfattheicher, 2011) and likelihood of helping others (Carbon \& Hesslinger, 2011). For example, participants in an experiment employing economic games were found more likely to transfer money to others in the presence of an image of watching eyes compared with a control image (Haley \& Fessler, 2005; Nettle et al., 2012; Oda et al., 2011). Positive watching-eyes effects were also reported on different real-life decisions, in field studies with naturalistic settings, including people paying more for their drinks via an honesty box (Bateson, Nettle, \& Roberts, 2006) and donating to charity (Powell, Roberts, \& Nettle, 2012). However, researchers have also reported unsuccessful replications of these experiments (e.g., Koornneef et al., 2018; Matsugasaki, Tsukamoto, \& Ohtsubo, 2015). To this end, Northover et al. (2017a) conducted two meta-analyses on the effects of surveillance cues on generosity and found no significant effect, warranting skepticism on surveillance cues and generosity. Northover et al. (2017b) also reported two meta-analyses on the effects of surveillance cues on moral judgment, which is self-reported possession of positive traits or religiosity. One meta-analysis showed insignificant effect, while the other produced a mean effect size on the edge of significance. These meta-analyses and studies call 
for further investigation to confirm how surveillance cues affect altruistic behavior and moral judgment, particularly paying attention to features of the environment, qualities of surveillance cues, and methods of analysis (Northover et al., 2017a).

More relevant to this study, the watching-eyes effects have been tested in relation to proenvironmental behavior change, such as littering (Bateson et al., 2013; Bateson et al., 2015; ErnestJones, Nettle, \& Bateson, 2011), disposal of recyclables (Francey \& Bergmüller, 2012), and nature conservation attitudes (Manesi, Van Lange, \& Poller, 2015). Importantly, Ernest-Jones, Nettle, and Bateson (2011) found that watching eyes reduced littering in café tables, especially when the café was rather empty. On the contrary, Bateson et al. (2013) identified that the image of watching eyes reduced littering in a (public) bicycle parking only when there were larger numbers of people in the vicinity. To this end, Bateson et al. (2013) suggested that the watching-eyes effects might be stronger when people are alone (as in the café experiment) or in a large, anonymous crowd (as in the bicycle parking experiment). Therefore, presenting surveillance cues in the privacy of a hotel room (when guests are "alone") will potentially result in a strong effect on pro-environmental behavior change. This provides theoretical explanation for the potential effectiveness of utilizing virtual assistant and robot to induce behavior change in hotel rooms.

\section{Machines, Agency, and Feedback}

Akin to cues of surveillance, people respond socially to cues of agency. It has been suggested that people tend to anthropomorphize things, attributing human characteristics on non-human objects (Epley et al., 2008). Further, researchers have also introduced the concept of automated social presence (ASP), which refers to the extent to which people perceive the presence of another social entity (van Doorn et al. 2017), and how it plays a role in human experience. Indeed, humans are prone to over-detecting agency, including interpreting humanlike nonverbal behavior in artificial entities (Rosenthal-von der Pütten, Krämer, \& Herrmann, 2018), and modifying their behavior accordingly (Epley, Waytz, \& Cacioppo, 2007). According to media equation and computers as social actors (CASA) studies, when computing technology is designed to convey social cues, users respond socially to it in the same manner as they respond to other people (Nass, Fogg, \& Moon, 1996; Nass, 
Steuer, \& Tauber, 1994). This behavior is believed to be automatic rather than rational (Fogg, 1998; 2003) and is often rooted in people's mindlessness when interacting with computers (Nass \& Moon, 2000). Consequently, the persuasive effects of technology on users' opinion and behavior can be comparable to those of human contacts. This indicates a great promise held by computing technology, and intentional agents such as digital assistants and social robots, as motivational actors to influence and change users' attitude and behavior (Mumm \& Mutlu, 2011; Tussyadiah, 2017). Findings and suggestions from recent research on consumer responses to service robots in tourism and hospitality provide support for this hypothesis (e.g., Murphy, Gretzel, \& Pesonen, 2019; Tussyadiah \& Park, 2018).

In terms of interventions for pro-environmental behavior change, social reinforcement through positive and negative social feedback (e.g., praise, compliment, and sign of disapproval) has been proven effective in incentivizing behavioral change (Bandura \& MacDonald, 1963). To this end, researchers have explored whether social reinforcements submitted by intelligent agents can be as effective as those submitted by humans (Midden \& Ham, 2008; 2009; Vossen, Ham, \& Midden, 2009; 2010). Based on the hypotheses of media equation studies (Nass, Fogg, \& Moon, 1996; Nass \& Moon, 2000; Nass, Steuer, \& Tauber, 1994), it was suggested that "an intelligent system that is perceived as social actor should be able to influence the behavior of a person that receives social feedback from the system" (Midden \& Ham, 2008; n.p.). A series of studies involving social feedback and energy conservation demonstrated that social feedback from an embodied agent (a robot) can create behavior change among humans (Midden \& Ham, 2008; Vossen, Ham, \& Midden, 2009; 2010). In terms of social feedback, Midden and Ham (2008) found that participants in the social feedback condition used less electricity than participants in factual feedback condition. In terms of agency, Ham and Midden (2008) demonstrated that feedback from a social agent (robot) was more effective than feedback from non-social agent (a lamp) in reducing electricity use, even when both used evaluative (social) feedback. These results suggest that type of agent (source of feedback) and type of feedback (factual vs. social feedback) have significant effect on pro-environmental behavior. These hypotheses have been confirmed in subsequent studies (Midden \& Ham, 2009; Vossen, Ham, 
\& Midden, 2009; 2010). An exception was one experiment from Ham and Midden (2009), who found that the greatest effects on user choice occurred after social feedback with low agency.

Following the aforementioned studies, it can be suggested that AI-powered virtual assistant and companion robot can provide cues of agency (through conversation and question answering) and cues of surveillance (always on), hence trigger some levels of automated social presence. Moreover, they can be designed to provide feedback to hotel guests to encourage resource conservation behaviors. Therefore, they can be used to verify the theories underlying the watching-eyes effects and to incentivize behavioral change through feedback mechanism incorporating social norms. The only apparent difference between virtual assistant and companion robot is their (physical) presence. While past studies have compared robotic agent to non-social agent, both physically present (tangible, embodied), the different effects of virtual assistants and robots have yet to be explored. Moreover, testing the effects of social feedback from different social agents will confirm and expand understanding of feedback as incentive for behavior change. In this study, social feedback is represented as social (verbal) expressions in the form of praise/ compliment, encouragement, and sign of approval/disapproval from a virtual assistant and a robot. The following are the main hypotheses of this study:

H1. Pro-environmental behavior intention will vary between virtual assistant and robot conditions.

H2. Pro-environmental behavior intention will be higher in social feedback condition.

\section{Factors Contributing to Pro-environmental Behavior Intention}

While this research focuses mainly on testing the effects of cues of intentional agents/surveillance and feedback on behavior change, it is important to recognize the effects relative to those of other factors. Thus, this study also considers attitudes towards interventions and personal factors associated with pro-environmental behavior to control for the intervention effects. It is noteworthy that the goal was not to be inclusive of all possible factors affecting pro-environmental behavior and intention (a comprehensive list of personal and social factors can be found in Gifford and Nilsson, 2014), but to control for factors that are most relevant to the likely outcomes of specific interventions designed in this study. These factors include: consumer acceptance of intervention strategies (Bos et al., 2013), 
personal norm (Gärling et al., 2003), descriptive norm (Elgaaied-Gambier, Monnot, \& Reniou, 2018; Steg \& Vlek, 2009) and social desirability.

For intervention strategies to be effective, especially those targeting consumer (consumption) behavior, it is important for the intervention to be consumer-driven (Andreasen, 2002) and that consumers accept these strategies (Bos et al. 2013). Referring to reactance vs rationalization theory (Laurin, Kay, \& Fitzsimmons, 2012), high level of acceptance towards an intervention will elicit rationalization, leading consumers to approve the intervention strategies and to adopt the intended behavior. In contrast, low levels of acceptance towards an intervention will cause consumers to resist performing the desired behavior (Laurin, Kay, \& Fitzsimmons, 2012). Studying consumer acceptance to interventions in food choice, Bos et al. (2013) suggested that acceptability of an intervention is associated with the effectiveness of the intervention to induce adoption of desired behavior. The following hypothesis is therefore suggested:

H3. Consumer acceptance of intervention positively affects pro-environmental behavior intention. Furthermore, in order to account for the specific intervention strategies examined in this study, acceptance of intervention will be tested for conditions involving virtual assistant and robot, as well as between presence and absence of social feedback. Highlighting the importance of social roles of robots in determining consumer response to intelligent agents, Wirtz et al. (2018) suggested adding social-emotional elements, including perceived humanness, social interactivity, and social presence of service robots, as factors influencing customer acceptance of service robots. Hence, the following hypotheses are suggested:

H4. Consumer acceptance of intervention will vary between virtual assistant and robot conditions.

H5. Consumer acceptance of intervention will be higher social feedback condition.

As personal norm represents moral obligation to perform pro-environmental behavior (Gärling et al., 2003), it is expected that high level of personal norm will lead to higher degree of environmentally sustainable behavior. This has been evidenced in previous studies (e.g., Dolnicar \& Leisch, 2008), Dolnicar, 2010). Descriptive norm and social desirability were considered in this study in order to explicate the roles of social norms in behavior intervention, which have been suggested in previous studies. Descriptive norm represents the extent to which the pro-environmental behavior is 
considered common (Steg \& Vlek, 2009) and is considered important to provide the baseline for social norm experiment in this study. It is expected that higher perceived descriptive norm will result in higher intention for pro-environmental actions. Prior studies suggest that self-reported proenvironmental behavior and intention are sensitive to social desirability bias (Juvan \& Dolnicar, 2016). Such effects thus need to be assessed and controlled. Kaiser et al. (1999) asserted that questionnaires occasionally reveal the intentions of a given study and participants might be inclined to fulfil researchers' expectations. Therefore, social desirability bias was included to control for the effects of other factors on pro-environmental actions and intention. The following hypotheses are suggested:

H6. Personal norm positively affects (H6a) acceptance of intervention and (H6b) pro-environmental behavior intention.

H7. Descriptive norm positively affects (H7a) acceptance of intervention and (H7b) proenvironmental behavior intention.

H8. Social desirability positively affects (H8a) acceptance of intervention and (H8b) proenvironmental behavior intention.

\section{Materials and Methods}

Stimuli. In order to achieve the objectives, this research employed a 2 × 2 factorial between-subjects experimental design (virtual assistant vs. robot and absence vs. presence of social feedback), providing four experimental conditions in the form of systematically varied scenarios, also known as vignettes (see Table S1). Along with the scenario, an image of a companion robot called Churi-Chan and that of a tablet, both placed on a nightstand, was presented to respondents in virtual assistant and robot conditions, respectively. These images of existing amenities in Henn na Hotel, Japan were used to support realism of the stimuli. Descriptions about ambient intelligence to monitor water and energy efficiency in the hotel room were provided to indicate that resource conservation is the local norm. This will align the norm psychology and pro-sociality hypotheses underlying the watching-eyes effects. Nisa, Varum, and Botelho's (2017) study suggested that interventions using social norms and nudges are proven effective. Following Acquisti et el.'s (2017) definition and classification of a 
nudge, providing feedback is considered a dimension of a nudge (i.e., nudging with information). Descriptions about feedback and historical comparison with previous and average consumption reflect the approach to providing social norm for the intervention (i.e., "Before bedtime, Nori will provide feedback on your water and energy consumption. Nori will also present the historical comparison of the room's water and energy consumption, enabling you to benchmark your performance with that of the previous days and with the average consumption."). In Social Feedback condition, statements representing social expressions from the agent were added (i.e., "When you saved more resources compared to the previous day, Nori will say in a happy voice: 'Good job saving energy and/or water today!', otherwise, Nori will say in a sad voice: 'Please try to save more energy and/or water tomorrow.'”). These statements were absent in No Social Feedback condition. Therefore, this study incorporates approaches that have been proven successful at inducing pro-environmental behavior change in order to isolate the effects of the different types of agents and presence of social feedback. The underlined text represents the manipulations in the scenarios, all other details were kept exactly the same, including the name of the agent, Nori. These scenarios were integrated into an online questionnaire.

Measurements. In order to simultaneously test the effects of personal factors on behavioral intention, the questionnaire includes the following constructs: three items measuring personal norm (Gärling et al., 2003), three items measuring descriptive norm (Gärling et al., 2003), and four items measuring social desirability (a short version from Crowne \& Marlowe, 1960). Measurements for consumers' acceptance of the intervention (five items) and pro-environmental behavioral intention (three items) were modified from questions posed in Bos et al.'s (2013) study, adapting the original context of healthy food choice to the targeted context of water and energy conservation in hotels. The personal norm and acceptance of intervention constructs were presented in 5-point scale with Strongly Disagree (1) - Strongly Agree (5) anchored statements. The social desirability construct were presented in True-checked (1)/False-unchecked (0) statements; total scores were then calculated. Proenvironmental behavior intention was presented in Highly Unlikely (1) - Highly Likely (5) anchored statements. 
Pre-Test. In order to assess the face validity and reliability of the constructs used in this research, specifically the modified items referring to experimental conditions (acceptance of pro-environmental behavior intervention), 33 academics from leading tourism institutions around the world whose selfstated research interests relate to information technologies and/or sustainability were asked to respond to the questionnaire in May 2018 to check for readability of scenarios and measurement items. Based on their feedback, adjustments were made to some expressions used in scenarios; two items measuring behavioral intention were slightly rephrased for clarity. Manipulation check for agency condition (virtual assistant vs. robot) and presence of social feedback (presence vs. absence of social feedback) resulted in $100 \%$ correct assignment of all conditions.

Pilot Study. The final questionnaire was distributed online to a panel of an international market research company in June 2018, targeting UK and US residents who have traveled and stayed overnight in a hotel at least once in the past six months. The aim of the pilot study was to assess the feasibility of data collection procedure and to test the reliability of the constructs included in the study. Respondents were randomly assigned to one of the four scenarios. To ensure the quality of collected data, several attention check questions (ACQs) were included in the questionnaire. One of the ACQs tested if respondents read and understood the scenario (i.e., respondents were ask to choose what has been asked to save, between "water consumption" [correct] or "air conditioning" [incorrect]); the others were presented in matrix questions (e.g., "Please select Somewhat agree."). Those who failed to answer the ACQs correctly were automatically terminated from the survey. A total of 134 respondents completed the survey. The results of pilot study suggested reliability of the constructs (Cronbach's Alpha values of all constructs, including those of the acceptance and intention, were above .70) and no further modification to the questionnaire was needed.

Main Study. The exact same questionnaire was distributed several days later (June 2018), targeting UK and US residents who have traveled and stayed overnight in a hotel at least once in the past six months who have not responded to the pilot study. Again, respondents were randomly assigned to one 
of the four scenarios. A total of 487 respondents completed the questionnaire. No statistically significant differences were found between respondents from pilot and main studies in terms of demographic characteristics. Some differences were found between UK and US respondents: respondents from the US reported higher levels of education and income in general compared to respondents from the UK (see Table S2).

Data Analysis. The details of measurement items and descriptive statistic of variables can be seen in Table S3 and the comparison between mean values from pilot and main studies can be found in Table S4. Only one item from acceptance of pro-environmental behavior intervention shows significant differences between pilot and main studies. Therefore, data from both studies were combined for further analysis $(N=621)$. First, a confirmatory factor analysis (CFA) was performed to test adequacy of the measurement model. Then, adequacy of the structural model was assessed for hypotheses testing. The MPlus program (Muthén \& Muthén 1998-2015) was utilized for analysis. The estimation applied in the analysis was MLM, a maximum likelihood parameter estimate with standard errors and a mean-adjusted chi-square test statistic (Satorra-Bentler corrections), which are robust to nonnormality. Several criteria were used to assess the validity, reliability, and goodness of fit for both measurement and structural models, following cut-off criteria suggested in previous studies on structural equation modeling (Hair, Black, Babin, \& Anderson 2010; Hu \& Bentler 1999).

\section{Results}

The results from CFA indicated that the goodness of fit of the measurement model as well as the validity and reliability of the latent constructs were supported. All factor loadings are above 0.6 (Table 1). Furthermore, average variance extracted (AVE) values of all latent constructs are well above the cut-off value of 0.5 (Hair et al., 2010), thus convergent validity was supported. Construct reliability (CR) and Cronbach's Alpha values of all latent constructs are above 0.7 (Hair et al., 2010), indicating reliability. Following Fornell-Larcker criterion for discriminant validity, square roots of AVE of all latent constructs are higher than their correlations with any other constructs (Table 2). The model fit criteria are supported $\left(\chi^{2}=336.404 ; \mathrm{df}=119 ; \mathrm{p}<0.001\right)$; the fit indices are above $0.9(\mathrm{Hu} \&$ Bentler, 1999): Comparative Fit 
Index $(C F I=0.974)$ and Tucker-Lewis Index $(T L I=0.967)$. The value of Root Mean Square Error of Approximation $(\mathrm{RMSEA}=0.054[0.047-0.061])$ indicates a moderate fit (between $0.05-0.08, \mathrm{Hu} \&$ Bentler, 1999) and the value of Standardized Root Mean Square Residual (SRMR=0.028) is below 0.9 (Hu \& Bentler, 1999). Therefore, adequacy of the measurement model was supported.

Table 1. Measurement Model: Outer Loadings, Average Variance Extracted (AVE), Composite Reliability (CR), and Cronbach's Alpha

\begin{tabular}{lcccc} 
& Loadings & AVE & CR & Cronbach's $\boldsymbol{\alpha}$ \\
\hline Personal Norm (PNORM) & & 0.717 & 0.883 & 0.874 \\
PNORM1 $\leftarrow$ PNORM & 0.884 & & & \\
PNORM2 $\leftarrow$ PNORM & 0.879 & & & \\
PNORM3 $\leftarrow$ PNORM & 0.772 & & & 0.891 \\
Descriptive Norm (DNORM) & & 0.736 & 0.893 & \\
DNORM1 $\leftarrow$ DNORM & 0.792 & & & \\
DNORM2 $\leftarrow$ DNORM & 0.915 & & & \\
DNORM3 $\leftarrow$ DNORM & 0.863 & & \multirow{2}{*}{0.939} \\
Acceptance of Intervention (ACCEPT) & & 0.761 & \\
ACCEPT1 $\leftarrow$ ACCEPT & 0.858 & & & \\
ACCEPT2 $\leftarrow$ ACCEPT & 0.855 & & & \\
ACCEPT3 $\leftarrow$ ACCEPT & 0.840 & & & \\
ACCEPT4 $\leftarrow$ ACCEPT & 0.906 & & & \\
ACCEPT5 $\leftarrow$ ACCEPT & 0.901 & & & \\
Pro-environmental Behavior Intention (INTENTPEB) & & 0.907 & 0.967 & \\
INTENTPEB1 $\leftarrow$ INTENTPEB & 0.968 & & & \\
INTENTPEB2 $\leftarrow$ INTENTPEB & 0.957 & & & \\
INTENTPEB3 $\leftarrow$ INTENTPEB & 0.932 & &
\end{tabular}

Table 2. Discriminant Validity: Fornell-Larcker Criterion

(1) Personal Norm

(1) Personal Norm $\quad 0.847$

(2) Descriptive Norm $\quad 0.197$

(3) Acceptance of Intervention $\quad 0.497$

(4) Pro-environmental Behavior Intention 0.521

(2)

(3)

(4)

Note: Correlation coefficients; square roots of Average Variance Extracted (AVE) in the diagonal

$\mathbf{0 . 8 7 2}$

0.836

$\begin{array}{ll}0.154 & \mathbf{0 . 8 7 2} \\ 0.209 & 0.836\end{array}$

0.154

The results from the structural model test are represented in Figure 1 and Table 3. Significant effects on pro-environmental behavior intention were found from interaction between type of agent and presence of social feedback $(\beta=0.096, p<0.050)$, personal norm $(\beta=0.128, p<0.001)$, and descriptive norm $(\beta=0.067, \mathrm{p}<0.010)$. The interaction effect of agency and presence of social feedback indicates that the intervention will be particularly effective if it was provided by virtual assistant with social feedback. Furthermore, guests with higher moral responsibility toward the environment and perceive that responsible behaviors are common practice in society tend to have higher intention to reduce resource consumption in hotel room. Lastly, the most important contributor 
to pro-environmental behavior intention is acceptance of intervention $(\beta=0.765, p<0.001))$. That is, a higher level of acceptance toward the intervention approach leads to a higher level of proenvironmental behavior intention. The influencing factors in the model account for $72 \%$ of variance in pro-environmental behavior intention $\left(R^{2}=0.722, p<0.001\right)$. Therefore, $\mathrm{H} 1$ and $\mathrm{H} 2$ were partially supported (interaction effect between type of agent and presence of social feedback), H3, H7b, and H8a were supported, and H8b was not supported.

Figure 1. Structural Model: Pro-environmental Behavior Intention

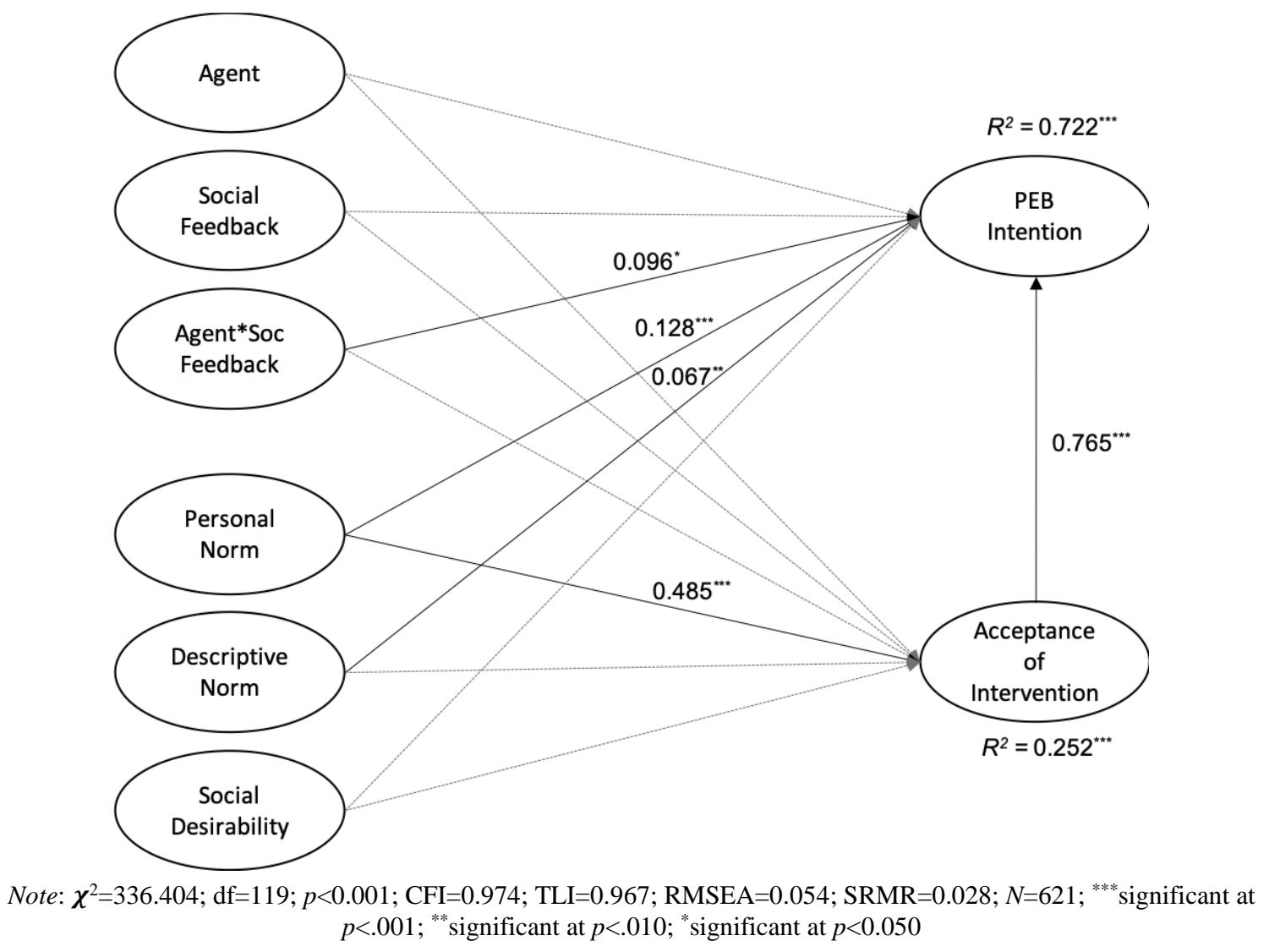

Table 3. Structural Model: Path Coefficients and Hypothesis Testing

Agent $\rightarrow$ Intention

Social Feedback $\rightarrow$ Intention

Agent*Social Feedback $\rightarrow$ Intention

Acceptance $\rightarrow$ Intention

Agent $\rightarrow$ Acceptance

Social Feedback $\rightarrow$ Acceptance

Agent*Social Feedback $\rightarrow$ Acceptance

Personal Norm $\rightarrow$ Acceptance

Personal Norm $\rightarrow$ Intention

Descriptive Norm $\rightarrow$ Acceptance

Descriptive Norm $\rightarrow$ Intention

Social Desirability $\rightarrow$ Acceptance

Social Desirability $\rightarrow$ Intention
Direct Effect

$-0.057(0.087)$

$-0.059(0.074)$

$0.096(0.018)$

$0.765(0.000)$

$0.046(0.372)$

$0.005(0.929)$

$-0.059(0.337)$

$0.485(0.000)$

$0.128(0.000)$

$0.058(0.147)$

$0.067(0.010)$

$-0.010(0.778)$

$0.014(0.551)$
Indirect Effect Hypothesis Testing

$0.034(0.371) \quad$ H1: Not Supported

-0.004 (0.929) H2: Not Supported

$-0.046(0.338) \quad$ New: Supported

H3: Supported

H4: Not Supported

H5: Not Supported

New: Not Supported

H6a: Supported

H6b: Supported

H7a: Not Supported

H7b: Supported

H8a: Not Supported

H8b: Not Supported 
A significant effect on acceptance of intervention was identified from personal norm $(\beta=0.485, p<0.001)$. None of the manipulations (type of agent, presence of social feedback, and interaction effect between the two) was found significant in influencing acceptance of intervention. It can be suggested that guests with higher moral responsibility toward the environment will evaluate pro-environmental behavior interventions using an intelligent agent more positively. The influencing factors in the model account for $25 \%$ of variance in acceptance of intervention $\left(R^{2}=0.252, p<0.001\right)$. Therefore, H6a was supported, while H4, H5, H6b, and H7a were not supported.

In order to confirm whether there are differences between US and UK respondents and between respondents from pilot study and those from main study, the model was run with multiple group analyses for both between residence groups and between study groups. No significant differences were found.

\section{Discussion}

This study did not find a direct significant effect of different types of intelligent agents on proenvironmental behavior intention amongst hotel guests. No one type of agent is more effective in inducing behavior change than the other. Considering that the aggregate mean values of proenvironmental behavior intention in both conditions are higher than the neutral value (virtual assistant: Mean $=3.78$, St. Dev. $=1.10$; robot: Mean $=3.76$, St. Dev. $=1.07)$, it can be suggested that both types of agent have the potential to induce pro-environmental behavior intention in hotel guests. From a theoretical perspective, the results suggest that cues of surveillance (and cues of agency) may be effective in both embodied and disembodied agents. To further elucidate the effects of these agents, further studies comparing interventions with each of these agents to those without an agent should be conducted.

Similarly, the presence of social feedback did not yield a significant direct effect on behavior intention. That is to say, whether or not the intelligent agent provides social feedback did not matter in making the intervention more effective. This seems to contradict a few previous studies suggesting that social reinforcement strengthens the impacts of cues of agency on socially accepted behavior (Vossen, Ham, \& Midden, 2009; 2010). However, upon further investigation on the interaction effect 
between the types of agent and the presence of social feedback, it becomes clear that the roles of social feedback in this context are more nuanced than what have been suggested previously (e.g., in Bateson et al., 2013), as they are intertwined with the source of feedback (i.e., type of agent). This study found a significant interaction effect between social feedback and type of agent, demonstrating that social feedback given by a virtual assistant is an effective intervention strategy. This is a similar finding to that of Ham and Midden (2009).

When social feedback was provided by a virtual assistant, its effect on pro-environmental behavior intention is positive and significant. This provides confirmation not only that social reinforcement from non-human agents can be effective in changing people's behavior, thus confirming media equation and CASA hypotheses (Midden \& Ham, 2008; Nass, Fogg, \& Moon, 1996; Nass \& Moon, 2000; Nass, Steuer, \& Tauber, 1994; Vossen, Ham, \& Midden, 2009; 2010), but also that watching-eyes effects can be observed in conditions where the "watcher" is not visible, a new proposition emerging from this study. That is, perception of another agent being 'present' in the room, also referred to as automated social presence (van Doorn et al., 2017; and as social presence in Wirtz et al., 2018), is sufficient to induce normative or pro-social behavior, regardless of the shape/form of the agent. This link between surveillance/agency cues of disembodied agent and behavior change is the main contribution of this study as it has not been proposed in previous studies on this topic. Though, because typical virtual assistants are integrated into smartphones and 'headless' devices (e.g., smart speakers), there is a slight chance that the image presented in the scenario, in which a tablet-like device was present, triggered a perception of embodiment (i.e., the agent 'lives' within the tablet) amongst respondents. Future studies should address this issue by testing different devices or making the agent truly pervasive by decoupling it from any devices.

On the contrary, receiving social feedback (social reinforcement) from an in-room companion robot may result in a decrease in pro-environmental behavior intention. Lack of familiarity or limited use cases might cause this discrepancy. While consumers might be familiar with a virtual assistant due to the prevalent use of smartphone (e.g., Siri), and smart home appliances (e.g., Alexa), the majority of them might not be used to the concept of a companion robot (see Kinsella, 2018). This suggests further elaboration on the perceived social roles of robots, especially when they are designed 
to inform and provide feedback to consumers to change their behavior. Furthermore, robot-related characteristics, such as the appearance of robot, might confound the effects of intervention (see Rosenthal-von der Pütten, Krämer, \& Herrmann [2018] and Tussyadiah \& Park [2018] for impacts of robot characteristics on user responses). In this case, Churi-Chan, a robot implemented in Henn na Hotel property in Japan, might be perceived as toy-like and thus unfit to "tell" hotel guests (humans) what to do or how to behave. Future research should be devoted to comparing behavior interventions using different types of robots. Other areas for future research include testing the effects of nudges by robot comparing between hotel guests staying on their own to those staying with a partner/family to further confirm the suggestion regarding stronger surveillance effects on consumers when they are alone (Bateson et al., 2013).

This study also identified significant effects of personal factors on evaluation of proenvironmental behavior intervention and behavior intention. Personal norm, which is perceived moral obligation to protect the environment, was significant in influencing acceptance of intervention and pro-environmental behavior intention. As expected, the higher consumers perceived that they are obliged to protect the environment, the higher their intention. This confirms previous studies on personal norm effects on pro-environmental intention and behavior (Dolnicar, 2010; Dolnicar \& Leisch, 2008; Gärling et al., 2003). It is noteworthy that the effect of personal norm on acceptance of intervention is higher than that on intention, suggesting that acceptance of intervention plays a significant role in bringing about pro-environmental intention, even amongst consumers with higher level of personal norm.

Evidence of significant but slight effect of descriptive norm on pro-environmental behavior intention was also found, while the effect on acceptance of intervention was not identified. This suggests that individuals who perceived that pro-environmental actions are common in society tend to have higher intention to conserve water and energy while staying at a hotel, regardless of whether or not they have higher level of acceptance of the intervention efforts. This confirms suggestions in previous studies (e.g., Steg \& Vlek, 2009). Despite using self-reported measures, which imply risk of sensitivity for social desirability bias (Juvan \& Dolnicar, 2016), this study did not find social 
desirability to significantly influence acceptance of intervention or behavior intention. Therefore, it can be suggested that the responses in this study did not suffer from social desirability bias.

The main contributor to pro-environmental behavior intention is acceptance of intervention, supporting earlier suggestion about the link between consumer acceptance and effectiveness of interventions in Bos et al. (2012). Consumers who have more favorable evaluation toward the intervention effort tend to have higher intention to behave more environmentally friendly, confirming the rationalization process suggested by Laurin, Kay, and Fitzsimmons (2012). This implies the importance of consumers' openness to being nudged, having a favorable attitude toward interventions, in the success of behavioral interventions for resource conservation.

\section{Conclusion and Implications}

The main objective of this research was to assess the effect of interventions involving intelligent agents in hotel rooms on pro-environmental behavior intention. A scenario-based experimental approach (vignette experiments) was employed by manipulating the types of agent (virtual assistant vs. robot) and social feedback (presence vs. absence of social feedback) to isolate these effects on behavior intention. This approach was considered important to confirm the novelty and relevance of contribution of this research relative to previous research using intentional agents for proenvironmental behavior change under the theoretical foundation behind the watching eyes effects (Midden \& Ham, 2008; Vossen, Ham, \& Midden, 2009; 2010). That is, while an intentional agent (a robot) has been compared to a non-intentional agent (a lamp), hence evidencing the effectiveness of (presence and absence of) agency cues on human behavior (Midden \& Ham, 2008; Vossen, Ham, \& Midden, 2009; 2010), the effectiveness of agency cues given by two types of intentional agents, embodied (a robot) and disembodied (a virtual assistant), has not been tested before.

Based on the results, key points emerging from this study are as follow: (1) virtual assistants and robots do not differ in their outcomes associated with pro-environmental behavior intervention; (2) social feedback from a virtual assistant yields positive outcomes, indicating it is an effective approach for behavior change intervention; (3) perception of presence of another agent in a room (i.e., automated social presence) is a sufficient cue of surveillance and is effective at inducing normative 
behavior; and (4) consumers' acceptance of being nudged plays a significant role in the success of behavior change intervention. This study contributes to theories linking surveillance psychology and behavioral sciences, enriching the discussion on approaches to behavioral intervention in a strategic area of resource conservation in tourism. As such, this research also contributes to finding new ways of leveraging emerging technologies for behavioral interventions in order to foster sustainability in tourism.

Several opportunities for future research can be suggested: (1) studies comparing interventions from intentional agents to those from other sources (e.g., printed messages) will assist in identifying relative effect sizes of different intentional agents on behavior change; (2) studies comparing interventions from different types (forms, appearances) of robotic agents could elucidate how consumer perception of the social roles of robots plays a role in adherence to nudges, adding to previous research on consumer reactions to robots in hospitality and tourism (e.g., Tung \& Law, 2017; Tussyadiah \& Park, 2018), and robot-related characteristics on human-robot interactions (e.g., Rosenthal-von der Pütten, Krämer, \& Herrmann [2018]); (3) studies targeting different consumer segments (e.g., solo travelers vs. those traveling with partner/family, travelers with differing trip purposes, etc.), especially with regards to attitude toward intelligent agents (e.g., acceptance of robotic applications in hotel) and resource conservation, will be necessary to complement testing different approaches to nudging in order to test the effectiveness of behavioral interventions for resource conservation in hotels.

From a managerial perspective, due to the emergence of application of intelligent agents in hotels, this study addresses a timely issue of how to better leverage technologies to help reducing the negative pressure of tourism on the environment. In particular, hotels integrating voice-activated virtual assistant such as Alexa in the rooms can be advised to apply nudges for resource-efficient behavior by incorporating social (evaluative) feedback on resource consumption. The evidence shown in this study of positive effects of social feedback coupled with a virtual agent signifies adoption of this intervention approach in hotels. While robots are considerably more novel to most consumers, and limited hotel companies have implemented them to date, the findings in this study can justify 
investment in using virtual assistants for pro-environmental behavior nudging in an attempt to save resources.

The main limitation of this study is reliance on self-report measures in assessing intervention outcomes through scenario-based quasi-experimental design, where participants were asked to imagine an intervention and then report their responses to the intervention (see Supplement for details). The effectiveness of intervention strategies were then assessed in terms of behavioral intention rather than actual behavior. To overcome the limitation originated from self-report measures (e.g., Holtgraves, 2004), social desirability bias was tested by including social desirability construct into the model, which yielded insignificant effect. While field experiments involving measurements of actual behavior are considered most rigorous and reliable in studies of behavioral change, it has been widely recognized in different disciplines that there is a predictable relationship between intentions and subsequent behavior (e.g., Cohen, 1992; Sheeran, 2002). Also, scenario-based experiments in surveys offer the internal validity of experiments (i.e., valid inference of cause-effect relationships between stimuli and reactions) augmented with the external validity of surveys (ability to reach broader populations) (Steiner, Atzmüller, \& Su, 2016). Furthermore, this study was conducted in anticipation of a broader application of robotics and AI-powered virtual agents in hotels. Therefore, it provides an early empirical evidence and informs the design of field experiments to be conducted on actual use of intelligent agents in hotel rooms, where actual behavior (water and energy consumption) of hotel guests should be measured in order to assess the effectiveness of intervention in real-life decisions of hotel guests.

\section{References}

Acquisti, A., Adjerid, I., Balebako, R., Brandimarte, L., Cranor, L.F., Komanduri, S., Leon, P.G., Sadeh, N., Schaub, F., Sleeper, M., Wang, Y., Wilson, S. (2017). Nudges for privacy and security: Understanding and assisting users' choices online. ACM Computing Surveys, 50(3), 44-. Andreasen, A.R. (2002). Marketing social marketing in the social change marketplace. Journal of Public Policy Marketing, 21, 3-13. doi: 10.1509/jppm.21.1.3.17602. 
Baca-Motes, K., Brown, A., Gneezy, A., Keenan, E., Nelson, L. (2013). Commitment and behavior change: Evidence from the field. Journal of Consumer Research, 39(5), 1070-1084.

Bandura, A., MacDonald, F.J. (1963). Influence of social reinforcement and the behavior of models in shaping children's moral judgment. The Journal of Abnormal and Social Psychology, 67(3), 274281.

Bargh, J.A. (2014). Our unconscious mind. Scientific American, 310, 30-37.

Bateson, M., Callow, L., Holmes, J.R., Redmond Roche, M.L., \& Nettle, D. (2013). Do images of 'watching eyes' induce behaviour that is more pro-social or more normative? A field experiment on littering. PLoS ONE, 8(12), https://doi.org/10.1371/journal.pone.0082055

Bateson, M., Nettle, D., Roberts, G. (2006). Cues of being watched enhance cooperation in a realworld setting. Biology Letters, 2(3), 412-414.

Bohdanowicz, P., Martinac, I. (2007). Determinants and benchmarking of resource consumption in hotels - Case study of Hilton International and Scandic in Europe. Energy and Buildings, 39(1), 82-95. https://doi.org/10.1016/j.enbuild.2006.05.005.

Bos, C., Van der Lans, I.A., Van Rijnsoever, F.J., Van Trijp, H.C.M. (2013). Understanding consumer acceptance of intervention strategies for healthy food choices: a qualitative study. BMC Public Health, 13, 1073. doi: 10.1186/1471-2458-13-1073.

Boyd, R., Richerson, P.J., Henrich, J. (2011). The cultural niche: Why social learning is essential for human adaptation. Proceedings of the National Academy of Sciences, 108 (26), 10918-10925.

Carbon, C.-C., Hesslinger, V.M. (2011). Cues-of-being-watched paradigm revisited. Swiss Journal of Psychology, 70, 2013-210.

Carlsson, R., Schimmack, U., Williams, D.R., \& Bürkner, P.-C. (2016). Bayesian evidence synthesis is no substitute for meta-analysis - A re-analyysis of Scheibehenne, Jamil and Wagenmaker (2016). Linneaus University Centre Labour Market and Discrimination Studies. https://lnu.se/globalassets/lmdswp20167.pdf

Chang, H.S., Huh, C., Lee, M.J. (2015). Would an energy conservation nudge in hotels encourage hotel guests to conserve? Cornell Hospitality Quarterly, 57(2), 172-183. 
Chudek, M., Henrich, J. (2011). Culture-gene coevolution, norm-psychology and the emergence of human prosociality. Trends in Cognitive Sciences, 15(5), 218-226.

Cohen, J. (1992). A power primer. Psychological Bulletin, 112:155-159. doi: 10.1037/00332909.112.1.155.

Crowne, D. P., \& Marlowe, D. (1960). A new scale of social desirability independent of psychopathology. Journal of Consulting Psychology, 24(4) 349-354.

Dolnicar, S. (2010). Identifying tourists with smaller environmental footprints. Journal of Sustainable Tourism, 18(6), 717-734.

Dolnicar, S, Leisch, F. (2008). Selective marketing for environmentally sustainable tourism. Tourism Management, 29(4), 672-680.

Elgaaied-Gambier, L., Monnot, E., Reniou, F. (2018). Using descriptive norm appeals effectively to promote green behavior. Journal of Business Research, 82, 179-191.

Epley, N., Waytz, A., Akalis, S., Cacioppo, J.T. (2008). When we need a human: Motivational determinants of anthropomorphism. Social Cognition, 26(2), 143-155.

Epley, N., Waytz, A., Cacioppo, J.T. (2007). On seeing human: a three-factor theory of anthropomorphism. Psychological Review, 114(4), 864-886.

Ernest-Jones, M., Nettle, D., Bateson, M. (2011). Effects of eye images on everyday cooperative behavior: A field experiment. Evolution and Human Behavior, 32, 172-178.

Farrow, K., Grolleau, G., Ibanez, L. (2017). Social norms and pro-environmental behavior: A review of the evidence. Ecological Economics, 140, 1-13.

Fogg, B.J. (1998). Persuasive computers: perspectives and research directions. Proceedings of the SIGCHI Conference on Human Factors in Computing Systems, pp. 225-232.

Fogg, B.J. (2003). Persuasive Technology: Using Computers to Change What We Think and Do. Amsterdam: Morgan Kauffmann.

Francey, D., Bergmüller, R. (2012). Images of eyes enhance investments in a real-life public good. PLoS ONE, 7(5), p. e37397.

Froehlich, J., Findlater, L., Landay, J. (2010). The design of eco-feedback technology. CHI 2010, April 10-15, 2010, Atlanta, GA, USA. 
Gärling, T., Fujii, S., Gärling, A., \& Jakobsson, C. (2003). Moderating effects of social value orientation on determinants of proenvironmental behavior intention. Journal of Environmental Psychology, 23, 1-9.

Gibson, D.K. (2017). The always-on digital assistant comes to your hotel room. AFAR. https://www.afar.com/magazine/the-always-on-digital-assistant-with-big-ears-comes-to-yourhotel-room

Gifford, R., Nilsson, A. (2014). Personal and social factors that influence pro-environmental concern and behavior. A review. International Journal of Psychology, 49(3), 141-157.

Gössling, S. (2002). Global environmental consequences of tourism. Global Environmental Change, 12(4), 283-302. https://doi.org/10.1016/S0959-3780(02)00044-4.

Hair, J.F., Black, W.C., Babin, B.J., Anderson, R.E. (2010). Multivariate Data Analysis. 7th Edition, Pearson, New York.

Haley, K.J., Fessler, D.M.T. (2005). Nobody's watching? Subtle cues affect generosity in an anonymous economic game. Evolution \& Human Behavior, 26(3), 245-256.

Ham, J., Midden, C. (2009). A robot that says “Bad!”: Using negative and positive social feedback from a robotic agent to save energy. 2009 4th ACM/IEEE International Conference on HumanRobot Interaction (HRI), La Jolla, CA, 2009, pp. 265-266.

Hawrylak, P.J., Nichols, W., Li, X., Johannes, T., DeCook, R., Mongold, K., Cornell, C., Flint, L.A., Singh, A. (2015). HydroSense: A self-powered wireless device for monitoring water usage in hotel showers. IEEE 2015 Global Humanitarian Technology Conference. https://ieeexplore.ieee.org/stamp/stamp.jsp?tp=\&arnumber=7343990

He, H.A., Greenberg, S., Huang, E.M. (2009). One size does not fit all: Applying the transtheoretical model to energy feedback technology design. Report 2009-943-22, Department of Computer Science, University of Calgary, Canada.

Holtgraves, T. (2004). Social desirability and self-reports: testing models of socially desirable responding. Personality and Social Psychology Bulletin, 30(2), 161-172. https://doi.org/10.1177/0146167203259930 
Hu, L.-t., Bentler, P. M. (1999). Cutoff criteria for fit indexes in covariance structure analysis: Conventional criteria versus new alternatives. Structural Equation Modeling, 6(1), 1-55.

Ivanov, S.H., Gretzel, U., Berezina, K., Sigala, M., Webster, C. (2019). Progress on robotics in hospitality and tourism: A review of literature. Journal of Hospitality and Tourism Technology, forthcoming.

Ivanov, S.H., Webster, C., Berezina, K. (2017). Adoption of robots and service automation by tourism and hospitality companies. Revista Turismo \& Desenvolvimento, 27/28, 1501-1517.

Jariyasunant, J., Abou-Zeid, M., Carrel, A., Ekambaram, V., Gaker, D., Sengupta, R., Walker, J.L. (2015). Quantified Traveler: Travel feedback meet the cloud to change behavior. Journal of Intelligent Transportation Systems, 19, 109-124.

Juvan, E., Dolnicar, S. (2016). Measuring environmentally sustainable tourist behaviour. Annals of Tourism Research, 59, 30-44.

Kaiser, F.G., Ranney, M., Hartig, T., Bowler, P.A. (1999). Ecological behavior, environmental attitude, and feelings of responsibility for the environment. European Psychologist, 4(2), 59-74.

Karlin, B., Zinger, J.F., Ford, R. (2015). The effects of feedback on energy conservation: A metaanalysis. Psychological Bulletin, 141(6), 1205-1227.

Keller, J., Pfattheicher, S. (2011). Vigilant self-regulation, cues of being watched and cooperativeness. European Journal of Personality, 25, 363-372. doi:10.1002/per.797

Kim, J.-Y., Hlee, S., Joun, Y. (2016). Green practices of the hotel industry: Analysis through the windows of smart tourism system. International Journal of Information Management, 36(6), 1340-1349.

Kim, S. (2016). Aloft launches the 'world's first voice-activated hotel rooms'. The Telegraph. https://www.telegraph.co.uk/travel/destinations/north-america/united-states/articles/aloftlaunches-the-worlds-first-voice-activated-hotel-room/

Kinsella, B. (2018). Consumer robots are dead; long live Alexa. USA Today. https://eu.usatoday.com/story/tech/talkingtech/2018/12/13/consumer-robots-dead-long-livealexa/2272460002/ 
Koornneef, E.J., Dariel, A., Elbarazi, I., Alsuwaidi, A.R., Robben, P.B.M., Nikiforakis, N. (2018). Surveillance cues do not enhance altruistic behavior among anonymous strangers in the field. PLoS ONE. https://doi.org/10.1371/journal.pone.0197959

Krátský, J., McGraw, J.J., Xygalatas, D., Mitkidis, P., \& Reddish, P. (2016). It depends who is watching you: 3-D agent cues increase fairness. PLOS ONE, 11(2), e0148845.

Laurin, K., Kay, A.C., Fitzsimons, G.J. (2012). Reactance versus rationalization: divergent responses to policies that constrain freedom. Psychological Science, 23, 205-209. doi: 10.1177/0956797611429468.

Manesi, Z., Van Lange, P.A.M., Pollet, T.V. (2015). Butterfly eyespots: Their potential influence on aesthetic preferences and conservation attitudes. PLOS ONE, https://doi.org/10.1371/journal.pone.0141433

Matsugasaki, K., Tsukamoto, W., Ohtsubo, Y. (2015). Two failed replications of the watching eyes effect. Letters on Evolutionary Behavioral Science, 6(2), 17-20.

Midden, C.J.H., Ham, J.R.C. (2008). The persuasive effects of positive and negative social feedback from an embodied agent on energy conservation behavior. In Proceedings of the British Society for the Study of Artificial Intelligence and the Simulation of Behaviour (AISB 2008), vol. 3, April $1-4,2008$

Midden, C.J.H., Ham, J.R.C. (2009). Using negative and positive social feedback from a robotic agent to save energy. In H. Gutscher, H-J. Mosler, B. Meyer, S. Mischke, \& M. Soland (Eds.), Abstract presented at the 8th Biennial Conference on Environmental Psychology, September 6-9, 2009, Zürich (p. 123). Lengerich: Pabst Science Publishers.

Mumm, J., Mutlu, B. (2011). Human-robot proxemics: Physical and psychological distancing in human-robot interaction. Proceedings of the 6th international conference on Human-robot interaction, pp. 331-338.

Murphy, J., Gretzel, U., Pesonen, J. (2019). Marketing robot services in hospitality and tourism: the role of anthropomorphism, Journal of Travel \& Tourism Marketing. doi: 10.1080/10548408.2019.1571983 
Nass, C., Fogg, B.J., Moon, Y. (1996). Can computers be teammates? International Journal of Human-Computer Studies, 45, 669-678.

Nass, C., Moon, Y. (2000). Machines and mindlessness: Social responses to computers. Journal of Social Issues, 56(1), 81-103.

Nass, C., Steuer, J., Tauber, E.R. (1994). Computers are social actors. CHI'94 Proceedings of the SIGCHI Conference on Human Factors in Computing Systems, pp. 71-78, New York, ACM.

Nettle, D., Nott, K., Bateson, M. (2012). 'Cycle thieves, we are watching you': Impact of a simple signage intervention against bicycle theft. PLoS ONE, 7 (2012).

Nisa, C., Varum, C., Botelho, A. (2017). Promoting sustainable hotel guest behavior: A systematic review and meta-analysis. Cornell Hospitality Quarterly, 58(4), 354-363.

Northover, S.B., Pederson, W.C., Cohen, A.B., Andrews, P.W. (2017a). Artificial surveillance cues do not increase generosity: Two meta-analyses. Evolution \& Human Behavior, 38(1), 144-153.

Northover, S.B., Pederson, W.C., Cohen, A.B., Andrews, P.W. (2017b). Effect of artificial surveillance cues on reported moral judgment: Experimental failures to replicate and two metaanalyses. Evolution \& Human Behavior, 38(5), 561-571.

Oda, R., Niwa, Y., Honma, A., Hiraishi, K. (2011). An eye-like painting enhances the expectation of a good reputation. Evolution and Human Behavior, 32, 166-171.

Ölander, F., Thøgersen, J. (2014). Informing versus nudging in environmental policy. Journal of Consumer Policy, 37, 341-356. https://doi.org/10.1007/s10603-014-9256-2

Pfattheicher, S., Keller, J. (2015). The watching eyes phenomenon: The role of a sense of being seen and public self-awareness. European Journal of Social Psychology, 45(5), 560-566.

Powell, K.L., Roberts, G., Nettle, D. (2012). Eye images increase charitable donations: Evidence from an opportunistic field experiment in a supermarket. Ethology, 118, 1096-1101.

Reese, G., Loew, K., Steffgen, G. (2014). A towel less: social norms enhance pro-environmental behavior in hotels. Journal of Social Psychology, 154(2), 97-100.

Roberts, G. (1998). Competitive altruism: from reciprocity to the handicap principle. Proceedings of the Royal Society of London Series B-Biological Sciences, 265, 427-431. 
Rosenthal-von der Pütten, A.M., Krämer, N.C., Herrmann, J. (2018). The Effects of humanlike and robot-specific affective nonverbal behavior on perception, emotion, and behavior. International Journal of Social Robotics, 10, 569-582. https://doi.org/10.1007/s12369-018-0466-7

Scheibehenne, B., Jamil, T., Wagenmakers, E.-J. (2016). Bayesian evidence synthesis can reconcile seemingly inconsistent results: The case of hotel towel reuse. Psychological Science, 27(7), 10431046.

Schultz, P.W. (2014). Strategies for promoting proenvironmental behavior: Lots of tools but few instructions. European Psychologist, 19, 107-117. https://doi.org/10.1027/1016-9040/a000163

Sheeran, P. (2002). Intention-behavior relations: A conceptual and empirical review. In: Stroebe, W, Hewstone, M. (Eds.). European Review of Social Psychology (pp. 1-36). John Wiley \& Sons Ltd.

Steg, L., Vlek, C. (2009). Encouraging pro-environmental behaviour: An integrative review and resarch agenda. Journal of Environmental Psychology, 29(3), 309-317.

Steiner, P.M., Atzmüller, C., Su, D. (2016). Designing valid and reliable vignette experiments for survey research: A case study on the fair gender income gap. Journal of Methods and Measurement in the Social Sciences, 7(2), 52-94.

Tung, V.W.S., \& Law, R. (2017). The potential for tourism and hospitality experience research in human-robot interactions. International Journal of Contemporary Hospitality Management, 29(10), 2498-2513. doi: 10.1108/IJCHM-09-2016-0520

Tussyadiah, I.P. (2017). Technology and Behavioral Design in Tourism. In Fesenmaier, D.R., \& Xiang, Z. (Eds.), Design Science in Tourism. Springer. DOI: 10.1007/978-3-319-42773-7_12

Tussyadiah, I.P., \& Park, S. (2018). Consumer evaluation of hotel service robots. In Stangl, B., \& Pesonen, J. (Eds.), Information and Communication Technologies in Tourism 2018 (pp. 308-320). Springer. doi: 10.1007/978-3-319-72923-7_24

UNWTO (2011). Tourism. Investing Energy and Resource Efficiency. http://sdt.unwto.org/sites/all/files/pdf/11.0_tourism.pdf

UNWTO (2012). Tourism in the Green Economy: A Background Report. https://www.eunwto.org/doi/pdf/10.18111/9789284414529 
UNWTO (2018). 2017 Annual Report. World Tourism Organization. https://www.eunwto.org/doi/pdf/10.18111/9789284419807

van Doorn, J., Mende, M., Noble, S. M., Hulland, J., Ostrom, A. L., Grewal, D., \& Petersen, J. A. (2017). Domo Arigato Mr. Roboto: Emergence of automated social presence in organizational frontlines and customers' service experiences. Journal of Service Research, 20(1), 43-58. https://doi.org/10.1177/1094670516679272

Vossen, S.H., Ham, J.R.C., Midden, C.J.H. (2009). Social influence of a persuasive agent: the role of agent embodiment and evaluative feedback. In Proceedings of the 4th International Conference on Persuasive Technology. Doi: 10.1145/1541948.1542007

Vossen, S.H., Ham, J.R.C., Midden, C.J.H. (2010). What makes social feedback from a robot work? Disentangling the effect of speech, physical appearance and evaluation. In Ploug T., Hasle P., Oinas-Kukkonen H. (eds), Persuasive Technology. PERSUASIVE 2010. Lecture Notes in Computer Science, vol. 6137. Springer: Berlin - Heidelberg

Warren, C., Becken, S., Nguyen, K., Stewart, R.A. (2018). Transitioning to smart sustainable tourist accommodation: Service innovation results. Journal of Cleaner Production, 201, 599-608.

Wirtz, J., Patterson, P., Kunz, W., Gruber, T., Lu, V.N., Paluch, S., and Martins, A. (2018). Brave new world: Service robots in the frontline. Journal of Service Management, 29(5), 907-931. 


\title{
Nudged by a Robot: \\ Responses to Agency and Feedback
}

\author{
Supplementary Materials
}

Table S1. Stimuli: Scenarios in 2 x 2 Factorial Between-Subjects Design

$\begin{array}{ll}\text { No Social } & \text { Virtual Assistant } \\ \text { Feedback } & \begin{array}{l}\text { Imagine you booked a hotel room for a one-week } \\ \text { holiday. Upon arrival, you learned that the hotel } \\ \text { adopts ambient intelligent technologies (via } \\ \text { multiple sensors) to monitor water and energy } \\ \text { efficiency and a voice-activated digital personal } \\ \text { assistant called Nori (similar to Apple's Siri and }\end{array} \\ & \text { Amazon's Alexa) to create a highly personalized, } \\ & \text { interactive, and intelligent guest room. } \\ & \text { The intelligent hotel room is designed to assist } \\ & \text { you to perform your daily activities in a } \\ & \text { more environmentally responsible way. Before } \\ \text { bedtime, Nori will provide feedback on your } \\ \text { water and energy consumption. Nori will also } \\ \text { present the historical comparison of the room's } \\ \text { water and energy consumption, enabling you to } \\ \text { benchmark your performance with that of the } \\ \text { previous days and with the average consumption. }\end{array}$

Social Feedback

\section{Robot}

Imagine you booked a hotel room for a one-week holiday. Upon arrival, you learned that the hotel adopts ambient intelligent technologies (via multiple sensors) to monitor water and energy efficiency and a voice-activated in-room companion robot called Nori to create a highly personalized, interactive, and intelligent guest room.

The intelligent hotel room is designed to assist you to perform your daily activities in a more environmentally responsible way. Before bedtime, Nori will provide feedback on your water and energy consumption. Nori will also present the historical comparison of the room's water and energy consumption, enabling you to benchmark your performance with that of the previous days and with the average consumption.

Imagine you booked a hotel room for a one-week holiday. Upon arrival, you learned that the hotel adopts ambient intelligent technologies (via multiple sensors) to monitor water and energy efficiency and a voice-activated in-room companion robot called Nori to create a highly personalized, interactive, and intelligent guest room.

The intelligent hotel room is designed to assist you to perform your daily activities in a more environmentally responsible way. Before bedtime, Nori will provide feedback on your water and energy consumption. Nori will also present the historical comparison of the room's water and energy consumption, enabling you to benchmark your performance with that of the previous days and with the average consumption. When you saved more resources compared to the previous day, Nori will say in a happy voice: "Good job saving energy and/or water today!" otherwise, Nori will say in a sad voice: "Please try to save more energy and/or water tomorrow."

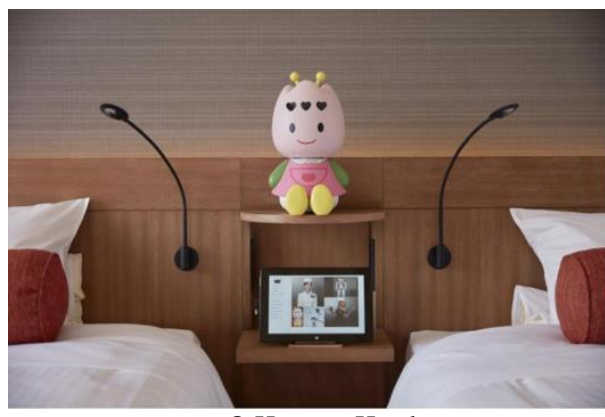

(c) Henn na Hotel 
Table S2. Demographic Characteristics of Respondents: US vs. UK

\begin{tabular}{|c|c|c|c|c|c|}
\hline Characteristics & $\begin{array}{c}\text { United } \\
\text { Kingdom }\end{array}$ & $\begin{array}{l}\text { United } \\
\text { States }\end{array}$ & Total & Chi-Square & Sig. \\
\hline Gender & & & & $.269(\mathrm{df}=1)$ & .604 \\
\hline Male & 162 & 153 & 315 & & \\
\hline Female & 150 & 154 & 304 & & \\
\hline Age & & & & $4.641(\mathrm{df}=1)$ & .461 \\
\hline 18 to 24 years & 10 & 8 & 18 & & \\
\hline 25 to 34 years & 20 & 26 & 46 & & \\
\hline 35 to 44 years & 32 & 39 & 71 & & \\
\hline 45 to 54 years & 59 & 60 & 119 & & \\
\hline 55 to 64 years & 103 & 108 & 211 & & \\
\hline 65 years and over & 88 & 67 & 155 & & \\
\hline Education & & & & $51.801(\mathrm{df}=7)$ & .000 \\
\hline Less than High School & 8 & 0 & 8 & & \\
\hline High School or equivalent & 91 & 37 & 128 & & \\
\hline Some College Experience & 71 & 54 & 125 & & \\
\hline Associate Degree & 17 & 42 & 59 & & \\
\hline Bachelor's Degree & 79 & 110 & 189 & & \\
\hline Master's Degree & 32 & 45 & 77 & & \\
\hline Doctoral Degree & 7 & 7 & 14 & & \\
\hline Advanced Professional & 7 & 11 & 18 & & \\
\hline Degree & & & & & \\
\hline Income (US\$) & & & & $110.179(\mathrm{df}=14)$ & .000 \\
\hline under 20,000 & 47 & 16 & 63 & & \\
\hline $20,000-29,999$ & 51 & 11 & 62 & & \\
\hline $30,000-39,999$ & 53 & 27 & 80 & & \\
\hline $40,000-49,999$ & 43 & 26 & 69 & & \\
\hline $50,000-59,999$ & 31 & 36 & 67 & & \\
\hline $60,000-69,999$ & 18 & 23 & 41 & & \\
\hline $70,000-79,999$ & 20 & 25 & 45 & & \\
\hline $80,000-89,999$ & 8 & 19 & 27 & & \\
\hline $90,000-99,999$ & 10 & 20 & 30 & & \\
\hline $100,000-109,999$ & 8 & 21 & 29 & & \\
\hline $110,000-119,999$ & 4 & 7 & 11 & & \\
\hline $120,000-129,999$ & 1 & 15 & 16 & & \\
\hline $130,000-139,999$ & 0 & 6 & 6 & & \\
\hline $140,000-149,999$ & 4 & 15 & 19 & & \\
\hline $150,000+$ & 12 & 41 & 53 & & \\
\hline
\end{tabular}


Table S3. Descriptive Statistics of Variables

Variables Mean

Personal Norm (PNORM)

PNORM1 - I personally feel I have a

moral obligation to protect the

environment.

PNORM2 - I personally feel it is

important that I behave in

environmentally responsible ways.

PNORM3 - Not being

environmentally responsible would

violate my personal principles.

Descriptive Norm (DNORM)

DNORM1 - Recycle paper, plastic,

metal cans, etc.

DNORM2 - Reduce waste by reusing

items such as water bottles, jars,

paper, plastic, etc.

DNORM3 - Conserve natural

resources such as water and energy.

Social Desirability (SDES)

Acceptance of Intervention (ACCEPT)

ACCEPT1 - Using ambient

intelligent technologies to monitor

energy and water efficiency in a hotel room is a good idea.

ACCEPT2 - Using an intelligent

agent to remind hotel guests to be

more environmentally responsible is

a good idea.

ACCEPT3 - Receiving feedback on

water and energy consumption while

staying in a hotel is a good idea.

ACCEPT4 - Being assisted by

technology to perform daily activities

in a more environmentally

responsible way is a good idea.

ACCEPT5 - Using technological

solutions to reduce the environmental

impacts of hotels is a good idea.

Pro-environmental Behavior Intention (INTENTPEB)

INTENTPEB1 - How likely are you

3.790

1.120

$-0.944$

0.098

0.364

0.196

to save more water and energy while

staying in this intelligent hotel room?

INTENTPEB2 - How likely are you

to reduce your water and energy

3.770

1.115

$-0.913$

0.098

0.334

0.196

consumption while staying in this

intelligent hotel room?

INTENTPEB3 - How likely are you

to behave more environmentally

responsible while staying in this

intelligent hotel room?

S.D.

kewness

S.E.

Kurtosis

S.E.

$\begin{array}{llllll}3.790 & 0.953 & -0.429 & 0.098 & -0.241 & 0.196 \\ 3.390 & 1.061 & -0.039 & 0.098 & -0.629 & 0.196 \\ 3.270 & 1.069 & 0.013 & 0.098 & -0.601 & 0.196 \\ 0.387 & 0.166 & 0.309 & 0.098 & -0.062 & 0.196 \\ 3.880 & 1.081 & -1.084 & 0.098 & 0.736 & 0.196 \\ & & & & & \\ 3.510 & 1.226 & -0.599 & 0.098 & -0.605 & 0.196 \\ & & & & & \\ 3.430 & 1.270 & -0.474 & 0.098 & -0.773 & 0.196 \\ 3.710 & 1.159 & -0.855 & 0.098 & 0.001 & 0.196\end{array}$

3.920

$-1.087$

0.098

0.752

0.196

0.196

\subsection{6}

.196

0.196

0.196

0.196

0.196

0.196

0.196

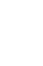

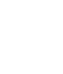


Table S4. Mean Differences: Pilot Study $(N=134)$ vs. Main Study $(N=487)$

Variables Pilot Study

Pilot Study Main Study

$\mathbf{t}(\mathbf{d f}=619) \quad$ Sig.

\begin{tabular}{lcccrrr} 
& Mean & St. Dev. & Mean & St. Dev. & & \\
\hline Personal Norm (PNORM) & & & & & & \\
PNORM1 & 4.110 & 0.907 & 4.060 & 0.916 & 0.634 & 0.526 \\
PNORM2 & 4.310 & 0.825 & 4.260 & 0.791 & 0.580 & 0.562 \\
PNORM3 & 3.910 & 1.007 & 3.890 & 1.022 & 0.256 & 0.798 \\
Descriptive Norm (DNORM) & & & & & & \\
DNORM1 & 3.790 & 0.943 & 3.790 & 0.957 & -0.039 & 0.969 \\
DNORM2 & 3.420 & 1.064 & 3.390 & 1.061 & 0.308 & 0.758 \\
DNORM3 & 3.280 & 1.072 & 3.270 & 1.070 & 0.049 & 0.961 \\
Social Desirability (SDES) & 0.434 & 0.287 & 0.454 & 0.060 & -0.672 & 0.502 \\
Acceptance of Intervention (ACCEPT) & 3.960 & 1.079 & 3.850 & 1.082 & 1.029 & 0.304 \\
ACCEPT1 & 3.660 & 1.177 & 3.460 & 1.237 & 1.614 & 0.107 \\
ACCEPT2 & 3.650 & 1.258 & 3.380 & 1.269 & 2.214 & 0.027 \\
ACCEPT3 & 3.820 & 1.136 & 3.670 & 1.165 & 1.304 & 0.193 \\
ACCEPT4 & 3.990 & 1.022 & 3.910 & 1.100 & 0.823 & 0.411 \\
ACCEPT5 & 3.880 & 1.048 & 3.770 & 1.139 & 1.031 & 0.303 \\
Pro-environmental Behavior Intention $(\mathrm{INTENTPEB)}$ & & & & \\
INTENTPEB1 & 3.900 & 1.054 & 3.730 & 1.129 & 1.583 & 0.114 \\
INTENTPEB2 & 3.840 & 1.068 & 3.720 & 1.145 & 1.150 & 0.250 \\
INTENTPEB3 & & & & &
\end{tabular}




\section{Nudged by a Robot: \\ Responses to Agency and Feedback}

\section{Statement of Contribution}

1. What is the contribution to knowledge, theory, policy or practice offered by the paper?

This research extends our knowledge of the social roles of intentional agents, such as AIpowered virtual assistant and robot, in influencing human behavior. As such, they can be used to provide interventions and nudges to target behavior change in support of sustainable tourism. This study contributes to theories linking surveillance psychology, media equation, and behavioral sciences, enriching the discussion on approaches to behavioral intervention in a strategic area of sustainable tourism. In practice, this study contributes to finding new ways of implementing emerging technologies, AI and robotics, for behavioral intervention to foster sustainability. Due to the emergence of application of intelligent agents in hotels, this study addresses a timely issue of how to create technological solutions to help reducing the pressure of tourism on the environment.

2. How does the paper offer a social science perspective/approach?

Our work provides a social science perspective as it contributes to the discourse of the use of technologies for behavioral change intervention in tourism and hospitality settings. This research focuses on the impacts of surveillance and social (agency) cues, given by intentional agents such as virtual assistant and service robot, on travelers' attitude and behavioral intention. It leverages the hypotheses behind norm psychology, surveillance psychology, and reputation-based partner choice models, as well as anthropomorphism and media equation, to investigate how consumers (humans) react to intervention given by machines. Hence, it contributes to a better understanding of the social roles of robotics and AI systems in influencing human behavior in general (social) settings, and in fostering specific behavior (i.e., resource conservation) in tourism/hospitality settings. 


\section{Nudged by a Robot: \\ Responses to Agency and Feedback}

\section{Authors' Bio}

Iis Tussyadiah is Reader in Hospitality and Digital Experience and Head of Department of Hospitality in the School of Hospitality and Tourism Management at University of Surrey. Her research interest lies in the intersection of digital technologies and tourism experiences.

Graham Miller is Professor of Sustainability in Business and Executive Dean of the Faculty of Arts and Social Sciences at University of Surrey, where he conducts research into business ethics, sustainable tourism and corporate social responsibility. He acts in an editorial capacity for several prestigious tourism journals and contributes his expertise to government bodies, trade associations and the UN. 